\title{
Effect of the inclination angle on the transient performance of a phase change material-based heat sink under pulsed heat loads"
}

\author{
Jiang $\mathrm{LU}^{1}$, Li-wu FAN ${ }^{\dagger 2}$, Yi ZENG ${ }^{3}$, Yu-qi XIAO ${ }^{2}, \mathrm{Xu} \mathrm{XU}^{4}$, Zi-tao YU ${ }^{2}$ \\ $\left({ }^{1}\right.$ School of Civil Engineering and Architecture, Zhejiang University of Science and Technology, Hangzhou 310023, China) \\ $\left({ }^{2}\right.$ Department of Energy Engineering, Zhejiang University, Hangzhou 310027, China) \\ $\left({ }^{3}\right.$ Department of Mechanical Engineering, Auburn University, Auburn 36849, USA) \\ $\left({ }^{4}\right.$ School of Metrological and Measurement Engineering, China Jiliang University, Hangzhou 310018, China) \\ †E-mail: liwufan@zju.edu.cn
}

Received Apr. 15, 2014; Revision accepted Aug. 12, 2014; Crosschecked Sept. 29, 2014

\begin{abstract}
The transient performance of a phase change material (PCM)-based heat sink may be affected by its inclination angle because natural convection usually occurs and dominates melting during the operation of the heat sink. An experimental setup was designed and used in this study that allows for the alternation of the inclination angle of the heat sink. The inclination angle was varied from $0^{\circ}$ to $90^{\circ}$ at increments of $15^{\circ}$, while two pulsed heat loads ( 20 and $40 \mathrm{~W}$ ) were adopted. 1-hexadecanol of a nominal melting temperature of $49^{\circ} \mathrm{C}$ was selected as the PCM. The transient performance of the heat sink was characterized by the temperature variations at the center of the heat spreader under various conditions. The results showed that the transient performance of the heat sink is able to be improved by simply increasing its inclination angle which then facilitates the natural convection during melting. However, the variation in the performance is not a monotonous function of the inclination angle. Although the time-averaged thermal resistances of the heat sink were shown to be only marginally lowered, the maximum operation times may be greatly extended under the given thermal conditions. For a heat load of $40 \mathrm{~W}$ and the maximum allowable temperature of $75^{\circ} \mathrm{C}$, the operation time of the heat sink is extended by up to nearly $67 \%$ at an inclination angle of $75^{\circ}$ when compared to that of the horizontal case. Based on the cases tested, the optimal inclination angle was found to lie between $60^{\circ}$ and $75^{\circ}$.
\end{abstract}

Key words: Heat sink, Inclination angle, Melting, Natural convection, Phase change material (PCM), Thermal energy storage, Thermal management

doi: 10.1631 jzus.A1400103

Document code: A

CLC number: TK121

\section{Introduction}

Highly-efficient thermal management technologies are of great practical interest in improving the safety and reliability of electronic devices (Garimella, 2006) and power batteries (Rao and Wang, 2011) with increasing power and the shrinking of the packaging. These should also be diverse to meet unique requirements for a variety of operating condi-

\footnotetext{
\$Corresponding author

* Project supported by the National Natural Science Foundation of China (No. 51276159)

(C) Zhejiang University and Springer-Verlag Berlin Heidelberg 2014
}

tions in the heat sources. As opposed to the active cooling options, air-cooling for example (Etemoglu, 2007; Fan et al., 2013b), a thermal energy storage (TES)-based thermal management technique enables a more energy-efficient passive or hybrid solution to the cooling of electronics/batteries. This technique is often implemented by employing a phase change material (PCM). The presence of a PCM serves as an energy buffer that is capable of rapidly extracting the excess heat from the target electronics/batteries before its final dissipation to the surroundings. Featuring reduced temperature rise and improved temperature uniformity, the thermal issues of electronics/ batteries subject to intermittent (e.g., pulsed or cyclic) 
loads may be well addressed by PCM-based thermal management techniques (Vesligaj and Amon, 1999; Al Hallaj and Selman, 2000; Evans et al., 2001; Krishnan and Garimella, 2004; Yoo and Joshi, 2004; Krishnan et al., 2005; Mills and Al-Hallaj, 2005; Kizilel et al., 2008; 2009; Sabbah et al., 2008; Faraji and El Qarnia, 2009; Duan and Naterer, 2010; Rao et al., 2011; Saha and Dutta, 2012).

Considering the low thermal conductivity associated with common PCM candidates, internal fins have been routinely introduced into PCM-based TES systems in an effort to improve their transient performance through enhancement of heat conduction (Fan and Khodadadi, 2011). The effects of internal fins on the performance of PCM-based heat sinks have thus been extensively studied in the literature with applications to electronics cooling (Akhilesh et al., 2005; Shatikian et al., 2005; 2008; Nayak et al., 2006; Kandasamy et al., 2008; Saha et al., 2008; Saha and Dutta, 2010; Hatakeyama et al., 2011; Hosseinizadeh et al., 2011; Baby and Balaji, 2012; Jaworski, 2012; Fan et al., 2013a). Natural convection, however, generally occurs in the molten PCM during operation (energy charging) of the PCM-based heat sinks (El Omari et al., 2011; Saha and Dutta, 2011). The random positioning of portable electronic devices indicates that if a PCM-based heat sink is equipped for such devices (Hodes et al., 2002; Alawadhi and Amon, 2003; Tan and Tso, 2004; Setoh et al., 2010; Wang and Yang, 2011; Tan and Fok, 2012), its cooling performance may not be constant due to its natural convection transient nature. The variations are mainly because of the inclination angle of the heat sink. Few studies have addressed the inclinationdependent melting behaviors (Webb and Viskanta, 1986; Ye et al., 2012; Kamkari et al., 2014) and the resulting performance of PCM-based heat sinks (Kandasamy et al., 2007; Wang et al., 2007; Fok et al., 2010; Yang and Wang, 2012). Among these studies, however, Kandasamy et al. (2007) and Fok et al. (2010) seem to be the only ones who have presented experimental efforts where these three inclination angles being examined were horizontal $\left(0^{\circ}\right)$, inclined at $45^{\circ}$ to horizontal, and vertical $\left(90^{\circ}\right)$. The exerted heat loads were up to $12 \mathrm{~W}$ that corresponds to a maximum heat flux of only about $0.5 \mathrm{~W} / \mathrm{cm}^{2}$ (neglecting the heat losses), indicating that the natural convection effects were relatively weak in their experimental studies.
In view of the existing studies on relatively low heat loads and limited inclination angles, exploration of the effects of a wider range of inclination angles and more intensive heat loads on the performance of PCM-based heat sinks is of great interest. Hence, to extend the existing knowledge in this area, this study aims at examining experimentally the influence of the inclination angle on the transient performance of a PCM-based heat sink subjected to intensive pulsed heat loads.

\section{Experiments}

\subsection{Experimental setup}

A prototype PCM-based heat sink was designed and tested. The core component in this experimental setup was the heating unit used to mimic the heat source. The heating unit was assembled into a sandwich-like structure in such a way that the top side of a round mica-insulated electric heater (Minco HM6807, with a diameter of $38.1 \mathrm{~mm}$ ) was attached to a round copper plate, while its bottom was attached to an insulated pad made of ceramic fabric paper. The mica heater, round copper plate, and insulated pad were of identical size. A square copper plate with a slightly larger size (side of $40 \mathrm{~mm}$ ) serving as the heat spreader was attached to the top surface of the heating unit (i.e., the top surface of the round copper plate), as shown in Fig. 1a. The heating unit was packaged with a bulk rectangular base made of Teflon ${ }^{\circledR}$. Such an

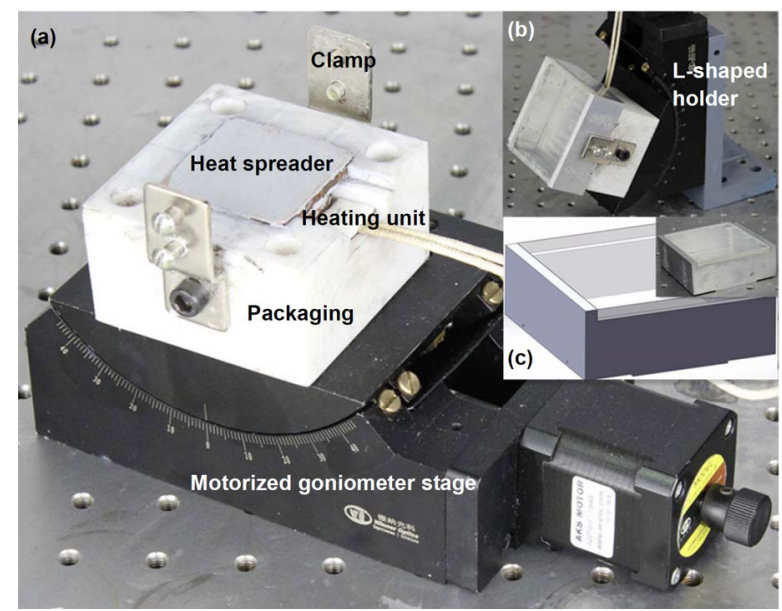

Fig. 1 Experimental setup positioned horizontally on a table (a) and mounted vertically on an L-shaped holder (b), and schematic diagram of the heat sink (c) (the inset is a photograph of the heat sink) 
integrated design of the heating unit enabled convenient installation and replacement of the heat sink.

The packaging was fixed on top of a motorized goniometer stage (WN04GA45, Winner Optics), which allows for an adjustment of the inclination angle from $-45^{\circ}$ to $45^{\circ}$ with an accuracy of $\pm 0.1^{\circ}$. As shown in Fig. 1b, the heating unit, along with the heat sink, may be installed on an L-shaped steel plate to extend the range of the inclination angle. In this way, the inclination angle (relative to horizontal) was able to be varied from $-45^{\circ}$ to $135^{\circ}$. A heat sink made of aluminum was mounted on top of the heating unit (not explicitly shown in Fig. 1a) and was firmly held in place by the two clamps. The structure of the heat sink is shown in Fig. 1c. The outer dimensions (length $\times$ width $\times$ height) of the heat sink were $80 \mathrm{~mm} \times 80 \mathrm{~mm} \times$ $30 \mathrm{~mm}$. A perspex plate lid was fabricated to cover the heat sink, which allows for visualized observation of melting occurring inside the heat sink. The lid was sealed carefully with a silicone sealant after the heat sink was filled with a PCM. The entire cooling system was actually of a hybrid type with a cooling fan being mounted on top of the heat sink and being operated at a constant air flow rate. The detailed assembly process and specifications of the various components were presented by Fan et al. (2013a).

\subsection{Experimental procedure}

In the present work, 1-hexadecanol $\left(\mathrm{C}_{16} \mathrm{H}_{34} \mathrm{O}\right)$ with a nominal melting point of $49^{\circ} \mathrm{C}$ was chosen as the PCM. As concluded by Fan et al. (2013a), a PCM with a relatively high melting point is preferred because of its better performance primarily due to faster recovery (re-solidification) for subsequent use. The selected PCM was pre-melted and degassed in a vacuum oven for $3 \mathrm{~h}$ prior to use. The molten PCM was then poured into the heat sink. The weight of the adopted PCM was $(60 \pm 0.1) \mathrm{g}$ for all experiments. Several type-T thermocouples (TCs), which were calibrated to have an accuracy of $\pm 0.2{ }^{\circ} \mathrm{C}$ prior to use, with a diameter of $1.0 \mathrm{~mm}$, were employed to monitor the temperature variations at various locations of the setup. The TC that was mounted at the center of the heat spreader was identified as the junction temperature of the heat source. The mica heater was powered by a digital DC power supply (RXN-3010D, Shenzhen Zhaoxin Electronic Instrument Equipment Co., Ltd., China) at two different power input levels of approximately 20 and $40 \mathrm{~W}$. The uncertainty of the exerted heating power was less than $\pm 0.1 \mathrm{~W}$. As mentioned above, such powers are much greater than the maximum value (about $12 \mathrm{~W}$ ) examined in related studies and are closer to the intensive heating conditions encountered in practical electronics cooling applications. During the entire course of pulsed heating, the power was kept constant at a set point and was then turned off after a prescribed heating duration. Transient temperature variations were monitored by $\mathrm{TC}$ readings that were logged by a digital data acquisition system (Agilent 34970A) at a frequency of $0.1 \mathrm{~Hz}$. All experiments were carried out in an air-conditioned room maintained at a temperature of $(21 \pm 1){ }^{\circ} \mathrm{C}$. The inclination angle was varied from $0^{\circ}$ to $90^{\circ}$ in increments of $15^{\circ}$. According to the combinations of input powers $(Q \approx 20$ and $40 \mathrm{~W})$ and inclination angles $\left(\alpha=0^{\circ}, 15^{\circ}, 30^{\circ}, 45^{\circ}, 60^{\circ}, 75^{\circ}\right.$, and $90^{\circ}$ ), a total of 14 different cases were considered. The definition of the inclination angle $\alpha$ (with respect to horizontal) is illustrated in Fig. 2.

It is evident that the inclination angle is equal to the angle between the heat flux $q^{\prime \prime}$ (perpendicular to the heat spreader surface) and gravity vectors. The two extreme cases, i.e., $\alpha=0^{\circ}$ and $90^{\circ}$, may be classified into melting above a heated horizontal wall and melting along a heated vertical wall, respectively. The heat fluxes $q^{\prime \prime}$ on the heat spreader surface and the heating durations are listed in Table 1 for the two heat loads.

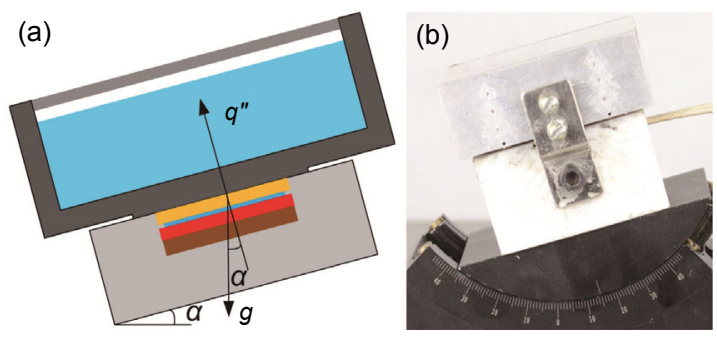

Fig. 2 Schematic diagram of the PCM-based heat sink showing the definition of the inclination angle (a) and photograph of the heat sink in an inclined case (b)

Table 1 Surface heat fluxes and heating durations of the two heat loads exerted

\begin{tabular}{ccccc}
\hline$Q(\mathrm{~W})$ & Current (A) & Voltage $(\mathrm{V})$ & $q^{\prime \prime}\left(\mathrm{W} / \mathrm{cm}^{2}\right)$ & Time $(\mathrm{min})$ \\
\hline 19.54 & 3.02 & 6.47 & 1.22 & 50 \\
39.30 & 9.14 & 4.30 & 2.46 & 23 \\
\hline
\end{tabular}


Neglecting the heat losses, the surface heat flux was as high as about $2.5 \mathrm{~W} / \mathrm{cm}^{2}$ which was much greater than those adopted in the previous experimental studies (Kandasamy et al., 2007; Fok et al., 2010). The heating durations were carefully chosen to assure that complete melting was achieved for all cases and that the maximum temperature rises were within a rational range. The cooling (re-solidification) periods were not monitored in the present study, because natural convection effects are expected to be negligible during solidification in such a configuration. Each case was repeated twice and excellent consistency was observed between the two runs of each case. The maximum discrepancies of the transient temperature variations were found to be less than $1{ }^{\circ} \mathrm{C}$. Therefore, the experimental data from the single runs are presented herein.

\section{Results and discussion}

\subsection{Transient temperature rises}

As mentioned, temperature readings of the $\mathrm{TC}$ mounted at the center of the heat spreader were considered as the cooling target. Comparisons of transient temperature variations among the various inclination angles are presented in Fig. 3 for the heat load of $20 \mathrm{~W}$ within a total duration of $50 \mathrm{~min}$.

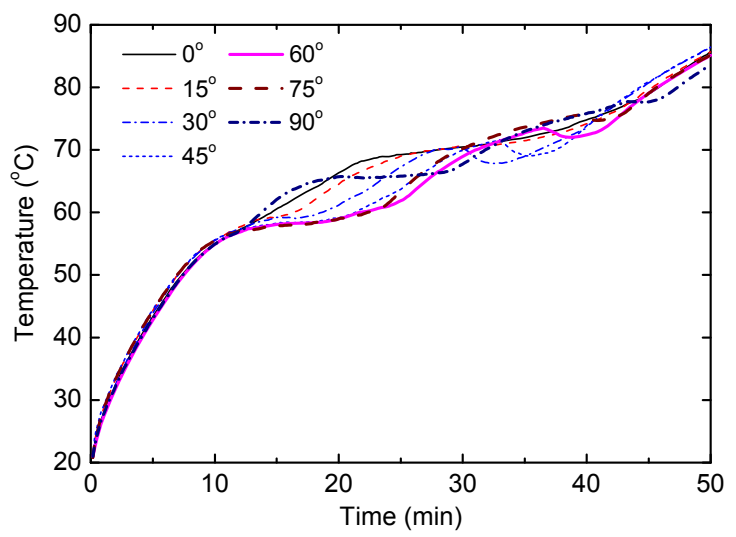

Fig. 3 Transient temperature rises at the center of the round copper plate for the heat sink operated at various inclination angles under the heat load of $20 \mathrm{~W}$

Based on the slope of the curves, several representative phases during the entire heating may be identified, i.e., pre-melting, melting, and postmelting. Initially, temperature rises rapidly prior to the onset of melting. After heating for about $12 \mathrm{~min}$ (corresponding to $58{ }^{\circ} \mathrm{C}$ ), the energy buffer began to play its role as the slope of the curves became much lower. At this time instant, the temperature of the TC was about $10^{\circ} \mathrm{C}$ higher than the melting temperature of the PCM (about $49^{\circ} \mathrm{C}$ ) because of the presence of thermal resistance between the heat spreader and the heat sink. Melting then lasted for about $30 \mathrm{~min}$, followed by a rapid temperature rise again after completion of melting.

As shown in Fig. 3, during the pre-melting phase, the curves corresponding to the various inclination angles almost converges to a single one. This clearly resulted from the fact that conduction was the dominant mode of heat transfer during this phase, which is not influenced by inclination. The curves then start departing from one another during the melting phase. This phase may be further separated into two stages, i.e., initial and developed, which can be indicated by the change of slope. For the horizontal case $\left(\alpha=0^{\circ}\right)$, the slope became much lower at around $22 \mathrm{~min}$. This inflection point roughly separates the two sub-stages during melting and indicates the transition of melting from conduction-dominated to convection-dominated. During the initial melting stage, the slope of the curves became smaller with increasing the inclination angle, until it reached $45^{\circ}$, and vice versa during the developed melting phase. This suggests that the effect of natural convection is more pronounced at greater inclination angles. In other words, melting tended to become convectiondominated at the initial stage for an inclined heat sink. This discrepancy can be interpreted in relation to the intensity of natural convection during melting. As it is well known, the intensity of natural convection can be measured by the Grashof number $(G r)$, which may be defined as

$$
G r=\frac{(g \cos \alpha) \beta q^{\prime \prime} L^{4}}{k v^{2}}
$$

where $g$ is the gravitational constant; $\beta, k$, and $v$ are the thermal expansion coefficient, thermal conductivity, and kinematic viscosity, respectively; and $L$ stands for the characteristic length. A pertinent characteristic length may be chosen as the height of the liquid phase along the direction of the heat flux. Hence, the characteristic length grows as melting proceeded, leading to the intensifying of the convection effect. 
Given the geometric configuration, thermal boundary condition, and thermophysical properties of the PCM, the instantaneous value of the Gr number is only determined by the inclination angle and the characteristic length. Despite a lack of direct visualized observation on the melt patterns (through the lateral walls of the heat sink), it is rational to speculate that during the initial stage of melting, the molten PCM was in the form of a thin layer along the bottom of the entire heat sink for the horizontal case $\left(\alpha=0^{\circ}\right)$, whereas if the heat sink was inclined $\left(\alpha>0^{\circ}\right)$, the molten PCM tended to rise and concentrate in the upper corner of the heat sink. Even if the amounts of molten PCM for the two cases were close (at the beginning of melting), the instantaneous characteristic lengths for the inclined cases were much greater than that for the horizontal cases. This leads to much greater instantaneous $G r$ numbers for the inclined cases, despite the slight lowering of the effective gravitational acceleration that is scaled by $\cos \alpha$ $\left(\cos \alpha<1\right.$ for $\left.\alpha>0^{\circ}\right)$. The discrepancy of the melt patterns is thus understood to be the primary cause of the departure of the curves for different inclination angles during melting. When the inclination angle became greater than $45^{\circ}$, the curves are rather consistent with one another, suggesting that the melt patterns for those inclination angles $\left(\alpha=45^{\circ}, 60^{\circ}\right.$, and $\left.75^{\circ}\right)$ were similar, except for the vertical case $\left(\alpha=90^{\circ}\right)$ which likely resulted from the uniqueness of the melt pattern. The instantaneous characteristic lengths of the horizontal and inclined cases became closer as melting proceeded and the curves finally converge together again, as shown in Fig. 3. Approaching completion of melting (around $42 \mathrm{~min}$ ), local troughs (undershoots) are found on the curves for $\alpha \geq 30^{\circ}$. This is attributed to the falling of a small piece of PCM that was previously attached to the transparent cover of the heat sink. Such phenomena were always observed in repeated experiments for these cases. The natural convection-induced melt patterns seem to be responsible for the formation of such isolated pieces of PCM in inclined cases when $\alpha \geq 30^{\circ}$. Therefore, this phenomenon is expected to be accompanied with intensive natural convection.

As shown in Fig. 3, after completion of melting, the slope of the curves become almost identical again and the maximum temperature rises are consistent with the end of heating. This is in accordance with the findings presented by Kandasamy et al. (2007) that the final temperature rise is almost independent of the inclination angle. This can be understood through the intensity differences of natural convection among the various inclination angles becoming negligible in fully molten PCM. The maximum relative difference is determined to be approximately $0.71\left(=\cos 45^{\circ} \%\right.$ $\cos 0^{\circ}$ ), in light of the fact that the instantaneous characteristic lengths were all equal to the height of the heat sink.

Comparisons of transient temperature variations among the various inclination angles for the heat load of $40 \mathrm{~W}$ within a total duration of $23 \mathrm{~min}$ are presented in Fig. 4. It is clear that the general trends are similar to what have been presented before, regardless of the heating power exerted. However, the curves deviate from one another to some extent during the pre-melting phase, which is likely due to variations of convective heat transfer coefficients along the lateral walls of the heat sink at the various inclination angles. The local troughs occurring at the end of melting are also found on the curves for all the inclined cases $(\alpha>$ $\left.0^{\circ}\right)$, except for the vertical configuration $\left(\alpha=90^{\circ}\right)$ where such a local trough is absent. The magnitudes of the troughs seem to be greater than those for the previous cases with the lower heat loads, which can be attributed to the inherently more intensive convection effect associated with the higher heat loads.

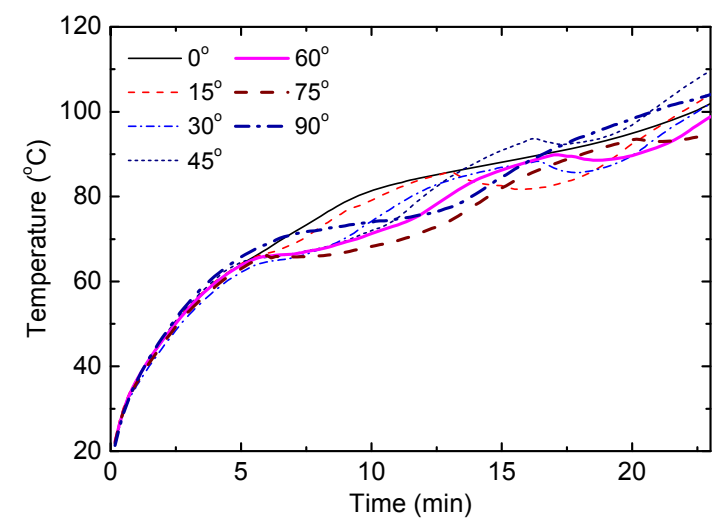

Fig. 4 Transient temperature rises at the center of the round copper plate for the heat sink operated at various inclination angles under the heat load of $40 \mathrm{~W}$

\subsection{Time-averaged thermal resistances}

Based on the above analysis on the transient temperature rises, a conclusion may be drawn qualitatively that the transient performance of the PCMbased heat sink tends to be better as the temperature 
rise is clearly suppressed during the melting phase with increasing the inclination angle. To provide a quantitative evaluation, the effective thermal resistance $(R)$ of the heat sink may be evaluated by

$$
R=\frac{T-T_{\infty}}{Q}
$$

where $T_{\infty}$ is the ambient temperature. It is noted that the thermal resistance defined in this way actually characterizes the performance of the hybrid system including both the PCM-based heat sink and the cooling fan. The average values of the timedependent thermal resistances for the two heat loads over their respective heating periods were calculated, as presented in Fig. 5.

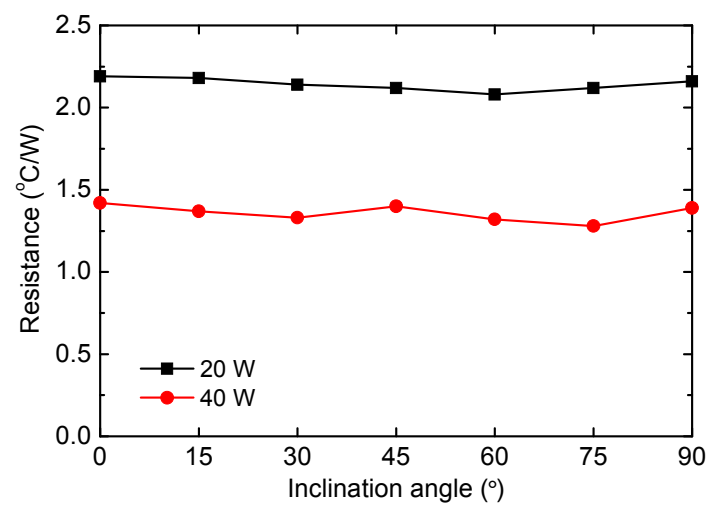

Fig. 5 Time-averaged effective thermal resistances of the PCM-based heat sink over the operation durations of the two heat loads at various inclination angles

At constant inclination angles, the thermal resistances of the heat sink at the higher heat load are consistently lower than those at the lower heat load, because the natural convection effect during melting was much more pronounced in the former case which improves the performance of the heat sink. It is shown that within the entire spectrum of the inclination angle, the variations of the time-averaged thermal resistances are not monotonous. For the case of $Q=$ $20 \mathrm{~W}$, the time-averaged thermal resistance gradually decreases and then rises with increasing the inclination angle. The minimum thermal resistance is found at $\alpha=60^{\circ}$ for this case. In contrast, two local troughs ( $\alpha$ $=30^{\circ}$ and $75^{\circ}$ ) are seen for the case of $Q=40 \mathrm{~W}$ with the one at $\alpha=75^{\circ}$ being the minimum.

However, the relative variations of the thermal resistances are less than $10 \%$ for both heat loads. That is, at a constant heat load, the thermal resistance of the PCM-based heat sink may be considered as nearly independent of the inclination angle. It is also interesting that the thermal resistances for the two extreme cases (horizontal and vertical) are nearly identical, regardless of the heat load applied, although their transient temperature rises and the associated melt patterns were essentially different.

\subsection{Maximum operation times}

In real-world applications, it is often required that the cooling target temperature is able to be maintained below a set point (the maximum allowable temperature) as long as possible. This serves as a measure to characterize the performance of heat sinks. If the set point is $75{ }^{\circ} \mathrm{C}$ (for commercial portable electronic devices), for the lower heat load $(20 \mathrm{~W})$, the various curves exceed this point at almost the same time instants around the end of melting (around $42 \mathrm{~min}$ ), as shown in Fig. 3. For this heat load, the maximum operation times of the heat sink at various inclination angles are compared in Table 2, where the extensions of operation time relative to that of the horizontal case $\left(\alpha=0^{\circ}\right)$ are also given. The resolution of the measured times is $10 \mathrm{~s}$ due to the interval of data logging.

Table 2 Measured operation times of the PCM-based heat sink at different inclination angles for $Q=20 \mathrm{~W}$ below the set point of $75^{\circ} \mathrm{C}$

\begin{tabular}{ccc}
\hline$\alpha\left({ }^{\circ}\right)$ & Operation time $(\mathrm{s})$ & Relative extension (\%) \\
\hline 0 & 2420 & - \\
15 & 2470 & 2.1 \\
30 & 2450 & 1.2 \\
45 & 2450 & 1.2 \\
60 & 2550 & 5.4 \\
75 & 2510 & 3.7 \\
90 & 2310 & -4.6 \\
\hline
\end{tabular}

It is shown that the operation time was only extended by a maximum of $5.4 \%$ while being placed at $\alpha=60^{\circ}$, which is consistent with the lowest thermal resistance for this case, whereas the operation time was shortened by $4.6 \%$ for the vertical case $\left(\alpha=90^{\circ}\right)$. On the contrary, the time to reach this set point spreads within a much wider range (during melting) for the heat load of $40 \mathrm{~W}$, as can be seen in Fig. 4. The measured operation times for this case are listed in Table 3. 
It is shown that the operation time is significantly extended by inclining the heat sink. The maximum extension by a factor of nearly $67 \%$ is found at $\alpha=75^{\circ}$ that is also consistent with the lowest thermal resistance as previously seen in Fig. 5. As discussed, such improvement on the transient performance of the PCM-based heat sink is primarily caused by the enhancement of natural convection during melting by altering the inclination angle. If the electronic device being cooled is operated within the melting phase of a PCM-based heat sink with pertinently chosen combinations of heat load and heat storage capacity, the performance of the heat sink can be intensified by simply inclining it to a certain angle to facilitate natural convection. As suggested by the present results, the optimal inclination angle may be around $75^{\circ}$. The enhanced performance, however, is strongly dependent on the given thermal conditions, especially the heat load, as well as the cooling target criteria.

Table 3 Measured operation times of the PCM-based heat sink at different inclination angles for $Q=40 \mathrm{~W}$ below the set point of $75^{\circ} \mathrm{C}$

\begin{tabular}{ccc}
\hline$\alpha\left(^{\circ}\right)$ & Operation time $(\mathrm{s})$ & Relative extension $(\%)$ \\
\hline 0 & 480 & - \\
15 & 520 & 8.3 \\
30 & 620 & 29.2 \\
45 & 670 & 39.6 \\
60 & 710 & 47.9 \\
75 & 800 & 66.7 \\
90 & 680 & 41.7 \\
\hline
\end{tabular}

\section{Conclusions}

The transient performance of a PCM-based heat sink was investigated experimentally in this paper with an emphasis on the effect of its inclination angle, which was also supplemental to the previous study (Fan et al., 2013a). The inclination angle of the heat sink was varied from $0^{\circ}$ to $90^{\circ}$ relative to horizontal, while two relatively intensive heat loads (20 and $40 \mathrm{~W}$ ) were adopted. It was shown that by facilitating natural convection, the temperature rises for the inclined cases were greatly suppressed during the initial stage of the melting phase, regardless of the heat load exerted. This was interpreted to be related to the instantaneous melt patterns during melting. Compari- son of the time-averaged thermal resistances of the heat sink at various inclination angles was shown to be consistent with that of the temperature rises. In general, the thermal resistance decreases with increasing the inclination angle for both heat loads, except for cases approaching the vertical configuration $\left(\alpha=90^{\circ}\right)$. The minimum thermal resistances were found at an inclination angle of $60^{\circ}$ and $75^{\circ}$ under the heat loads of $20 \mathrm{~W}$ and $40 \mathrm{~W}$, respectively. However, the minimums were only up to $10 \%$ lower than their respective baseline values for the horizontal cases, because the inclination effect was negligible during both the pre-melting and post-melting phases.

On the contrary, for a given combination of heat load and maximum allowable temperature of the electronic device being cooled, the maximum operation time may be extended by simply inclining the heat sink. It was shown that such an extension can be achieved by a factor up to nearly $67 \%$ for the heat load of $40 \mathrm{~W}$ and a set point of $75^{\circ} \mathrm{C}$. The optimal inclination angle was found to lie between $60^{\circ}$ and $75^{\circ}$ based on the cases studied. The enhanced performance of the PCM-based heat sink, however, was only able to be realized when the target devices were operated within the melting phase. The performance was strongly dependent on the given thermal conditions including both the heat load and the cooling target.

\section{References}

Akhilesh, R., Narasimhan, A., Balaji, C., 2005. Method to improve geometry for heat transfer enhancement in PCM composite heat sink. International Journal of Heat and Mass Transfer, 48(13):2759-2770. [doi:10.1016/j. ijheatmasstransfer.2005.01.032]

Alawadhi, E.M., Amon, C.H., 2003. PCM thermal control unit for portable electronic devices: experimental and numerical studies. IEEE Transactions on Components and Packaging Technologies, 26(1):116-125. [doi:10.1109/ TCAPT.2003.811480]

Al Hallaj, S., Selman, J.R., 2000. A novel thermal management system for electric vehicle batteries using phase-change material. Journal of the Electrochemical Society, 147(9): 3231-3236. [doi:10.1149/1.1393888]

Baby, R., Balaji, C., 2012. Experimental investigations on phase change material based finned heat sinks for electronic equipment cooling. International Journal of Heat and Mass Transfer, 55(5-6):1642-1649. [doi:10.1016/j. ijheatmasstransfer.2011.11.020]

Duan, X., Naterer, G.F., 2010. Heat transfer in phase change materials for thermal management of electric vehicle battery modules. International Journal of Heat and Mass Transfer, 53(23-24):5176-5182. [doi:10.1016/j.ijheatmasstransfer. 2010.07.044] 
El Omari, K., Kousksou, T., Guer, Y.L., 2011. Impact of shape of container on natural convection and melting inside enclosures used for passive cooling. Applied Thermal Engineering, 31(14-15):3022-3035. [doi:10.1016/j. applthermaleng.2011.05.036]

Etemoglu, A.B., 2007. A brief survey and economical analysis of air cooling for electronic equipments. International Communications in Heat and Mass Transfer, 34(1):103113. [doi:10.1016/j.icheatmasstransfer.2006.08.005]

Evans, A.G., He, M.Y., Hutchinson, J.W., et al., 2001. Temperature distribution in advanced power electronics systems and the effect of phase change materials on temperature suppression during power pulses. Journal of Electronic Packaging, 123(3):211-217. [doi:10.1115/1.1370376]

Fan, L.W., Khodadadi, J.M., 2011. Thermal conductivity enhancement of phase change materials for thermal energy storage: a review. Renewable and Sustainable Energy Reviews, 15(1):24-46. [doi:10.1016/j.rser.2010.08.007]

Fan, L.W., Xiao, Y.Q., Zeng, Y., et al., 2013a. Effects of melting temperature and the presence of internal fins on the performance of a phase change material (PCM)-based heat sink. International Journal of Thermal Sciences, 70:114126. [doi:10.1016/j.ijthermalsci.2013.03.015]

Fan, L.W., Khodadadi, J.M., Pesaran, A.A., 2013b. A parametric study on thermal management of an air-cooled lithiumion battery module for plug-in hybrid electric vehicles. Journal of Power Sources, 238:301-312. [doi:10.1016/j. jpowsour.2013.03.050]

Faraji, M., El Qarnia, H., 2009. Passive cooling of protruding electronic components by latent heat of fusion storage. Journal of Electronic Packaging, 131(2):021011. [doi:10. $1115 / 1.3103953]$

Fok, S.C., Shen, W., Tan, F.L., 2010. Cooling of portable hand-held electronic devices using phase change materials in finned heat sinks. International Journal of Thermal Sciences, 49(1):109-117. [doi:10.1016/j.ijthermalsci.2009. 06.011]

Garimella, S.V., 2006. Advances in mesoscale thermal management technologies for microelectronics. Microelectronics Journal, 37(11):1165-1185. [doi:10.1016/j.mejo. 2005.07.017]

Hatakeyama, T., Ishizuka, M., Takakuwa, S., et al., 2011. Experimental and thermal network study on the performance of a pins studded phase change materials in electronic device cooling. Journal of Thermal Science and Technology, 6(1):164-177. [doi:10.1299/jtst.6.164]

Hodes, M., Weinstein, R.D., Pence, S.J., et al., 2002. Transient thermal management of a handset using phase change material (PCM). Journal of Electronic Packaging, 124(4): 419-426. [doi:10.1115/1.1523061]

Hosseinizadeh, S.F., Tan, F.L., Moosania, S.M., 2011. Experimental and numerical studies on performance of PCMbased heat sink with different configurations of internal fins. Applied Thermal Engineering, 31(17-18):3827-3838. [doi:10.1016/j.applthermaleng.2011.07.031]

Jaworski, M., 2012. Thermal performance of heat spreader for electronics cooling with incorporated phase change material. Applied Thermal Engineering, 35:212-219. [doi:10. 1016/j.applthermaleng.2011.10.036]

Kamkari, B., Shokouhmand, H., Bruno, F., 2014. Experimental investigation of the effect of inclination angle on convectiondriven melting of phase change material in a rectangular enclosure. International Journal of Heat and Mass Transfer, 72:186-200. [doi:10.1016/j.ijheatmasstransfer. 2014.01.014]

Kandasamy, R., Wang, X.Q., Mujumdar, A.S., 2007. Application of phase change materials in thermal management of electronics. Applied Thermal Engineering, 27(17-18): 2822-2832. [doi:10.1016/j.applthermaleng.2006.12.013]

Kandasamy, R., Wang, X.Q., Mujumdar, A.S., 2008. Transient cooling of electronics using phase change material (PCM)-based heat sinks. Applied Thermal Engineering, 28(8-9):1047-1057. [doi:10.1016/j.applthermaleng.2007. 06.010]

Kizilel, R., Lateef, A., Sabbah, R., et al., 2008. Passive control of temperature excursion and uniformity in high-energy Li-ion battery packs at high current and ambient temperature. Journal of Power Sources, 183(1):370-375. [doi:10. 1016/j.jpowsour.2008.04.050]

Kizilel, R., Sabbah, R., Selman, J.R., et al., 2009. An alternative cooling system to enhance the safety of Li-ion battery packs. Journal of Power Sources, 194(2):1105-1112. [doi:10.1016/j.jpowsour.2009.06.074]

Krishnan, S., Garimella, S.V., 2004. Analysis of a phase change energy storage system for pulsed power dissipation. IEEE Transactions on Components and Packaging Technologies, 27(1):191-198. [doi:10.1109/TCAPT.2004.825758]

Krishnan, S., Garimella, S.V., Kang, S.S., 2005. A novel hybrid heat sink using phase change materials for transient thermal management of electronics. IEEE Transactions on Components and Packaging Technologies, 28(2):281-289. [doi:10.1109/TCAPT.2005.848534]

Mills, A., Al-Hallaj, S., 2005. Simulation of passive thermal management system for lithium-ion battery packs. Journal of Power Sources, 141(2):307-315. [doi:10.1016/j. jpowsour.2004.09.025]

Nayak, K.C., Saha, S.K., Srinivasan, K., et al., 2006. A numerical model for heat sinks with phase change materials and thermal conductivity enhancers. International Journal of Heat and Mass Transfer, 49(11-12):1833-1844. [doi:10. 1016/j.jiheatmasstransfer.2005.10.039]

Rao, Z., Wang, S., 2011. A review of power battery thermal energy management. Renewable and Sustainable Energy Reviews, 15(9):4554-4571. [doi:10.1016/j.rser.2011.07.096]

Rao, Z., Wang, S., Zhang, G., 2011. Simulation and experiment of thermal energy management with phase change material for ageing $\mathrm{LiFePO}_{4}$ power battery. Energy Conversion and Management, 52(12):3408-3414. [doi:10.1016/j. enconman.2011.07.009]

Sabbah, R., Kizilel, R., Selman, J.R., et al., 2008. Active (air-cooled) vs. passive (phase change material) thermal management of high power lithium-ion packs: limitations of temperature rise and uniformity of temperature distribution. Journal of Power Sources, 182(2):630-638. [doi:10. 1016/j.jpowsour.2008.03.082]

Saha, S.K., Dutta, P., 2010. Heat transfer correlations for PCMbased heat sinks with plate fins. Applied Thermal Engineering, 30(16):2485-2491. [doi:10.1016/j.applthermaleng. 2010.06.021]

Saha, S.K., Dutta, P., 2011. Effect of melt convection on the 
optimum thermal design of heat sinks with phase change material. Journal of Enhanced Heat Transfer, 18(3):249259. [doi:10.1615/JEnhHeatTransf.v18.i3.60]

Saha, S.K., Dutta, P., 2012. Thermal management of electronics using PCM-based heat sink subjected to cyclic heat load. IEEE Transactions on Components, Packaging and Manufacturing Technology, 2(3):464-473. [doi:10. 1109/TCPMT.2011.2180021]

Saha, S.K., Srinivasan, K., Dutta, P., 2008. Studies on optimum distribution of fins in heat sinks filled with phase change materials. Journal of Heat Transfer, 130(3):034505. [doi:10.1115/1.2804948]

Setoh, G., Tan, F.L., Fok, S.C., 2010. Experimental studies on the use of a phase change material for cooling mobile phones. International Communications in Heat and Mass Transfer, 37(9):1403-1410. [doi:10.1016/j.icheatmasstransfer.2010. 07.013]

Shatikian, V., Ziskind, G., Letan, R., 2005. Numerical investigation of a PCM-based heat sink with internal fins. International Journal of Heat and Mass Transfer, 48(17):36893706. [doi:10.1016/j.ijheatmasstransfer.2004.10.042]

Shatikian, V., Ziskind, G., Letan, R., 2008. Numerical investigation of a PCM-based heat sink with internal fins: constant heat flux. International Journal of Heat and Mass Transfer, 51(5-6):1488-1493. [doi:10.1016/j.ijheatmasstransfer.2007. 11.036]

Tan, F.L., Tso, C.P., 2004. Cooling of mobile electronic devices using phase change materials. Applied Thermal Engineering, 24(2-3):159-169. [doi:10.1016/j.applthermaleng. 2003.09.005]

Tan, F.L., Fok, S.C., 2012. Numerical investigation of phase change material-based heat storage unit on cooling of mobile phone. Heat Transfer Engineering, 33(6):494-504. [doi:10.1080/01457632.2012.624852]
Vesligaj, M.J., Amon, C.H., 1999. Transient thermal management of temperature fluctuations during time varying workloads on portable electronics. IEEE Transactions on Components and Packaging Technologies, 22(4):541-550. [doi:10.1109/6144.814970]

Wang, X.Q., Mujumdar, A.S., Yap, C., 2007. Effect of orientation for phase change material (PCM)-based heat sinks for transient thermal management of electronic components. International Communications in Heat and Mass Transfer, 34(7):801-808. [doi:10.1016/j.icheatmasstransfer.2007. 03.008]

Wang, Y.H., Yang, Y.T., 2011. Three-dimensional transient cooling simulations of a portable electronic device using PCM (phase change materials) in multi-fin heat sink. Energy, 36(8):5214-5224. [doi:10.1016/j.energy.2011.06.023]

Webb, B.W., Viskanta, R., 1986. Natural-convection-dominated melting heat transfer in an inclined rectangular enclosure. International Journal of Heat and Mass Transfer, 29(2):183-192. [doi:10.1016/0017-9310(86)90226-7]

Yang, Y.T., Wang, Y.H., 2012. Numerical simulation of three-dimensional transient cooling application on a portable electronic device using phase change material. International Journal of Thermal Sciences, 51:155-162. [doi:10.1016/j.ijthermalsci.2011.08.011]

Ye, W., Zhu, D., Wang, N., 2012. Effect of the inclination angles on thermal energy storage in a quadrantal cavity. Journal of Thermal Analysis and Calorimetry, 110(3): 1487-1492. [doi:10.1007/s10973-011-2035-2]

Yoo, D.W., Joshi, Y.K., 2004. Energy efficient thermal management of electronic components using solid-liquid phase change materials. IEEE Transactions on Device and Materials Reliability, 4(4):641-649. [doi:10.1109/TDMR. 2004.840854]

\section{中文祭要:}

\section{本文题目：倾斜角度对基于相变材料的散热器在脉冲式热负荷作用下瞬时性能的影响}

Effect of the inclination angle on the transient performance of a phase change materialbased heat sink under pulsed heat loads

研究目的: 通过实验方法定量研究在相变材料较为剧烈的熔化传热过程中散热器倾斜角度的改变对其瞬 时性能所产生的影响。

创新要点: 定量研究在倾斜角度从水平到垂直时, 储能式散热器在脉冲式热负荷作用下瞬时性能的变化 规律，并在所研究的工况范围内给出了最优的倾斜角度参考值。

研究方法: 采用电加热方法模拟电子器件所产生的热源, 通过调节电压改变脉冲式热负荷的强度和作用 时间，并根据热电偶测量所得的加热表面温度变化来表征储能式散热器的瞬时性能。

重要结论: 在一定的倾斜角度下工作, 可以有效提升基于相变材料的储能式散热器的瞬时性能。在加热 功率为 $40 \mathrm{~W}$ 、以 $75{ }^{\circ} \mathrm{C}$ 为目标时，其有效保护时间的相对增长可达约 $67 \%$ 。

关键词组：散热器；倾斜角；相变材料；储热；热管理 